\title{
Analyzing the Millennials' Intention towards Purchasing Reusable Shopping Bags (Evidence from Bali)
}

\author{
Ni Kadek Yuni Antaria, Christian Haposan Pangaribuan ${ }^{b}$ \\ a, b Sampoerna University, Jakarta, Indonesia \\ ${ }^{a}$ kadek.antari@my.sampoernauniversity.ac.id \\ b christian.pangaribuan@sampoernauniversity.ac.id
}

\begin{abstract}
Objective - This study aims to analyze the millennials intention in Bali towards purchasing reusable shopping bags, the study extends the Theory of Planned Behavior (TPB).

Methodology - The data were collected by using online questionnaire in Bali. The total sample of this study is 227 respondents.

Findings - The finding of this study shows that Environmental Knowledge, Personal Belief, and Social Influence significantly affect the attitude of customers to purchase reusable shopping bags. Personal Belief becomes the dominant variable affecting consumer's attitude. Meanwhile, Government Regulation and Media Exposure have no significant influence on the attitude towards purchasing reusable shopping bags. Attitude significantly influences Intention to Purchase reusable shopping bags, while Intention to Purchase reusable shopping bags gives a significant effect on Pro-Environmental Behavior.

Novelty - In this study, the researchers extend the existing Theory of Planned Behavior and add environmental knowledge to show the fact that everyone is aware of the environment degradation issue and admit that the issue is everyone's responsibility.

Keywords: Theory of Planned Behavior; Pro-environmental Behavior; Purchase Intention

JEL Classification: R11, M38, N50

Article info: Received 5 March 2021; Revised 5 April 2021; Accepted 8 May 2021

Article Correspondence: christian.pangaribuan@sampoernauniversity.ac.id

Recommended Citation: Antari, N. K. Y. \& Pangaribuan, C. H. (2021). Analyzing the Millennials' Intention

towards Purchasing Reusable Shopping Bags (Evidence from Bali). Journal of Multidisciplinary Issues, 1(1), 22-31.
\end{abstract}

\section{INTRODUCTION}

The increase in global environmental degradation has become the most significant issue globally (Kishore \& Anand, 2013). This environmental degradation has become a challenge to living life due to the negative impact on humans and the surrounding environment. Many evidence shows that this issue's primary cause is human-induced (Choudhary \& Chauhan, 2015). People are using plastic bags in their daily life mainly for shopping purposes which environmentally-wise are dangerous products. The phenomenon related to this issue is that people have realized that their purchasing behavior directly impacts environmental degradation, e.g., global warming, climate changes, and problem-related ecology.

Nevertheless, people continue their behavior to consume harmful products to the environment, such as plastic bags. However, the current industry has introduced eco-friendly products that could minimize the number of plastic wastes. This kind of eco-friendly product comes with the reusable movement (Pangaribuan et al., 2020). Furthermore, eco-friendly products show that everyone is aware of the environmental degradation issue and admit that the ecological problem is everyone's responsibility. Hence, it will come up with the new consumption decision to buy eco-friendly products. 
The movement of reducing plastic waste has gained a serious response from the Governor of Bali Province. On December 24, 2018, Wayan Koster, the governor of Bali Province, announced a ban on plastics such as single-use of shopping bags (Louise, 2019). It has been stipulated in Gubernatorial Regulation (Pergub) No. 97/2018, expressing hope that the policy would lead to a 70 percent decline in Bali's marine plastics within a year. This policy was made to suppress the use of single-use plastics for all people, such as producers, distributors, suppliers, and business actors, including individuals (The Jakarta Post, 2018). Balinese have a considerable interest in preserving the environment by using reusable shopping bags.

Furthermore, up until now, reusable shopping bags have become a new trend in Bali (Gapura Bali, 2019). Many stores, supermarkets, and traditional markets have implemented reusable shopping bags for society. Today, Balinese bring their shopping bags while purchasing their daily needs (The Jakarta Post, 2018).

The decreased numbers of plastic bags accept the products and the ban of plastics used that has been implemented by many stores, traditional markets, supermarkets, and another shopping center in Bali (The Jakarta Post, 2018). The researcher chose to emphasize the millennial generation for this research because this generation has the highest percentage of willingness to purchase eco-friendly products (Joshi \& Rahman, 2015). Moreover, the millennials have more power to spread the influence of using new trends of products. Furthermore, the present research is to understand the factors affecting the millennials in Bali to purchase eco-friendly products such as reusable shopping bags.

\section{LITERATURE REVIEW}

\section{TPB (Theory of Planned Behavior)}

To analyze the factor influencing the reusable shopping bag purchasing behavior, the writers utilize the Theory of Planned Behavior (TPB) model. TPB is the theory used to describe the relationship between various variables and the purchase intention toward green products. TPB theory is often used in many studies on customer behavior. Moreover, this theory is used as the variable that explains a person's intention, describing the person's behavior. TBP theory is the expansion of TRA (Theory of Reasoned Action), which is the model that was developed by Fishbein and Ajzen (1975), which defines the links between attitude, beliefs, intention, norms, and behavior of individuals. According to the previous study, TRA and TPB models are often used to explain the relations between attitude, belief, purchase intention, social influence, and consumer behavior toward a particular object in marketing (Setyawan et al., 2018). In TPB, the model is determined by behavior intention by attitude toward behavior, subjective norm, and perceived behavior control. These three-variable lead to the formation of behavior intention then turn into influencing the behavior (Zhang et al., 2018).

\section{Millennials}

The Millennials, born between the years 1980 and 2000, are closer to the new millennium and raised in a more digital age (Nichols \& Smith, 2015). According to a study by Johnson (2015), the Millennials were born between 1980 and 1995. They also refer to them as the children of the Baby Boomers generation. This study also stated that the Millennials are heavily influenced by the trends that affected them and their Boomer parents. The characteristics of the Millennials are regarded as being more supportive of equal rights for minorities and more open-minded.

\section{Reusable Shopping Bags}

The function of reusable shopping bags in line with waste management includes reducing, reuse, and recycling. In other words, reusable shopping bags is one of the adoption products from the $3 \mathrm{R}$ (reduce, reuse, and recycle) movement. Moreover, Arifani and Haryanto (2018) stated that reusable shopping bags match the reduced concept since the material used in reusable shopping bags is eco-friendly. This research also argues that the behavior of using reusable shipping bags predicted by the TPB that all of the consumers' 
decision according to some reasons can be predicted by perceived behavioral control, attitude, and subjective norm.

\section{Pro-Environmental Behavior}

Pro-environmental behavior is described as the behavior that generally considers as the protective way of environmental behavior or a tribute to the healthy environment. The ecological behavior related to environmental science or ecology is evaluated according to its impact on the environment and labeled as environmentally friendly or unfriendly (Krajhanzl, 2010). According to the study by Ones et al. (2015), pro-environmental behavior describes as the individual behaviors contributing to environmental sustainability (such as limiting energy consumption, avoiding waste, recycling, and environmental activism).

\section{Environmental Knowledge}

Environmental knowledge refers to people's knowledge about their surroundings as an ecologically interconnected system, and people try to get involved in environmental sustainability development (Setyawan et al., 2018). According to the study from (Lee, 2017), environmental knowledge is personal knowledge about the environmental issue and general knowledge of the ecosystem's concept, fact, and relationship. Polonsky et al. (2012) further discuss that environmental knowledge can be divided into specific knowledge or general knowledge. Meanwhile, the previous study has considered that environmental knowledge is the particular knowledge; other studies used general knowledge to determine the relationship between pro-environmental behavior and environmental knowledge (Lee, 2017). Li et al. (2019) argue that environmental knowledge refers to the people's understanding and knowledge related to the environmental issue and environmental changes.

\section{Government Regulation}

Government regulation is the government's law to protect the environment and solve the environmental degradation issue. The environmental regulations can encourage the customers to obtain more green products and create a positive relationship between government regulation and green purchase intention (Ayodele et al., 2017). A study from Kishore et al. (2013) finds that the Malaysian government has implemented numerous strategies, including government regulation, to promote the reusable products to be consumed among the netizens. The government has been used its role to create social interest through regulation and law. The government developing sustainable consumption and preserve the environmental by applied the regulation and policies.

\section{Media Exposure}

The existence of media has been used to transform many specific problems into major public issues, especially environmental issues and conflicts. The study from Qader and Zainuddin (2011) argues that advertiser activity using various media to communicate product benefit to the target audience. For instance, print advertisements are often used to communicate detailed information and establish a brand image, commercial television is often used for public promotion, and interest product packaging to attract consumers' attention. Based on Schultz and Lauterborul's (1993) study, the media exposure gives the listener, reader, and viewer an opportunity to hear and see an advertising message in a particular media that directly influences the customers' perception. Another research from Bharucha (2018) mentioned that young people purchase the existence of media influences decision, they more interested in gathering information from a variety of media.

\section{Personal Belief}

Personal belief becomes one of the indicators that impact the customers to purchase an eco-friendly product. Personal belief is defined as the individual's belief that behaving and acting in a particular way is 
wrong or right (Al-shaaban \& Nguyen, 2014). This study finds that personal belief positively impacts Chinese consumer attitude and customers' intention toward purchasing organic food. According to Whaley and Costen's (2019) study, personal belief determines the personal rules of behavior that individuals learn socially among individuals within the same society and direct action in certain situations. Based on Doran and Larsen's (2016) study, personal belief is related to the self-concept that is experienced as the moral obligation for an individual to perform a certain behavior. In the environmental context, personal belief as the moral obligation influences the individual to protect the environment adequately.

\section{Social Influence}

Social influence plays an important role in purchase decisions and customer behavior. Mainly, consumer purchase decisions depend on other people's preference and information from other sources in their environment. Kian et al. (2017) stated that social influence affects an individual based on the behavior of others such as family, friends, and group of individuals. In terms of shopping activities, social influence means that individuals can influence others whether people will buy the products. This previous study found that social influence has a significant and positive impact on the purchase intention toward social media websites (Kian et al., 2017). Social influence becomes one of the factors that greatly affect attitude (Anam, 2014). This study indicates that social influence as the independent variable influences the purchase intention of Android smartphones as the dependent variable.

\section{Attitude}

Attitude is one of the particular designs in the TPB framework. Zhang et al., (2019) define attitude as a psychological way people can consistently favor or disfavor a specific object. This previous research has studied the relationship between purchase intention and attitude for eco- friendly products This resulted in a fundamental variable when predicting consumers' purchase intention. Moreover, Arifani and Haryanto (2018) define attitude as an action that indicates what customers like and dislike. It can be said that attitude is an evaluation created by consumers related to their likes and dislikes on some external stimulus.

\section{Purchase Intention}

Ajzen (1991) stated that attitude positively impacts purchase intention, one of the variables attached in TPB. The intention is the individual willingness to perform particular behavior and is essentially determined by three factors. One of the common factors is the individual's attitude toward involvement in the behavior that is recognized as purchasing attitude (Al-shaaban \& Nguyen, 2014). According to Jaafar (2018), purchasing intention is related to attitude, perception, and behavior. Furthermore, purchase intention is the efficient tool used to predict the purchasing process; the individual will be driven by their intention to purchase the products in certain stores. A different study from Tuan and Vinh (2016) defined purchase intention as to what the customers plan to buy. Consumers with high intentions to purchase a product will pay at a higher rate than those who have no intention to purchase the products.

\section{METHODOLOGY}

In this study, the population was taken from the millennials in Bali, including the 9 districts of Bali (Badung, Denpasar, Singaraja, Gianyar, Klungkung, Karangasem, Jembrana, Bangli, and Tabanan). The questionnaire was directly given to the respondents that are qualified for the study, categorized as millennials. In this study, the researcher used a non-probability technique to select a group of respondents from the large population, knowing that some of the population does not have a chance to be surveyed. Non-probability sampling is often associated with the qualitative and research design, which tends to focus on a small population and intended to examine a real-life phenomenon. The participants do not need to be representative, but a clear rationale is necessary to include some cases or individuals rather than others 
(Taherdoost, 2018). In this study, non-probability sampling was chosen to get time efficiently since the duration is limited. The researcher managed to obtain 227 respondents in total for the sample size.

\section{RESULTS AND DISCUSSION}

To check the validity and reliability test, the researchers examine the questionnaire using KMO (KaiserMeyer-Olkin) concept and anti-image analysis. Based on this concept, the validity standard used to analyze should be greater than 0.5 . When the result is less than 0.5 , it means that the questionnaire is not valid. Moreover, the reliability test, it will be tested using Cronbach Alpha from each variable. By using this, the value should be greater than 0.7 ; if the value is less than 0.7 , the variables item considered as not reliable. The researcher assessed the validity and reliability test through a pre-test done by acquiring an answer from 30 respondents. In detail, the questionnaire included eight variables by having three different questions of each item. In total, there are 24 items on the overall questionnaire. Based on the result, all of the variables item is valid and reliable.

Table 1. Multicollinearity Test Result

\begin{tabular}{clcc}
\hline \multirow{2}{*}{ Model } & \multicolumn{1}{c}{ Variables } & \multicolumn{2}{c}{ Collinearity Statistics } \\
\cline { 3 - 4 } & & Tolerance & VIF \\
\hline \multirow{2}{*}{1} & Environmental Knowledge (X1) & 0.455 & 2.198 \\
& Government Regulation (X2) & 0.436 & 2.296 \\
\multirow{2}{*}{1} & Media Exposure (X3) & 0.490 & 2.040 \\
& Personal Belief (X4) & 0.733 & 1.364 \\
& Social Influence (X5) & 0.433 & 2.311 \\
\hline 2 & Attitude & 1.000 & 1.000 \\
\hline 3 & Purchase Intention & 1.000 & 1.000 \\
\hline
\end{tabular}

Table 1 shows the multicollinearity test from each model. The multicollinearity test in this study aims to determine whether the independent variables have a high correlation or not with the dependent variable. The rule of this multicollinearity test is when the tolerance value is above 0.1 and VIF is below 10, the variables can be categorized as free of multicollinearity. As a result, the correlation of this independent and dependent variable cannot be disturbed. After conducting a Multicollinearity test using SPSS for the model, below is the result.

Table 2 shows the multiple and linear regression result of each model, the results show that the R-value for model 1 is 0.814 indicating a strong correlation in an overall linear relationship. Based on $\mathrm{R}$ coefficient rules, it stated that the value of the coefficient determination is higher than 0.1 . Therefore, when the result is greater than 0.1, it means that the linear regression is strong. Furthermore, the researcher also analyzes the value of the R-square. The result of the $\mathrm{R}$ square will help to describe how much the influence of all independent variables toward the dependent variable in the model. As the result show, the value of $\mathrm{R}$ square is 0.663 which indicate that $66.3 \%$ of attitude to purchase reusable shopping bags influence by Environmental Knowledge, Government Regulation, Media Exposure, Personal Belief, and Social Influence. The rest of $33.7 \%$ is influenced by other factors or variables which not included in this model.

Table 2. Multiple Regression \& Simple Linear Regression Test Result

\begin{tabular}{ccccc}
\hline Model & $\mathbf{R}$ & $\mathbf{R}^{\mathbf{2}}$ & Adjusted R & Error \\
\hline $1^{*}$ & 0.814 & 0.663 & 0.655 & 1.090 \\
$2^{* *}$ & 0.776 & 0.602 & 0.600 & 1.040 \\
$3^{* * *}$ & 0.826 & 0.682 & 0.680 & 0.960 \\
\hline * Predictors: Social Influence, Personal Belief, Media Exposure, Environmental Knowledge, Government Regulation \\
** Predictors: Attitude \\
*** Predictors: Purchase Intention
\end{tabular}


Moreover, for model 2 the result of R-value is 0.776 , which means a strong correlation in an overall linear relationship. Based on $\mathrm{R}$ coefficient rules, it stated that the value of the coefficient determination is higher than 0.1 . Therefore, when the result is greater than 0.1 , meaning that the linear regression is strong.

Table 3. Coefficients (Models 1, 2, and 3)

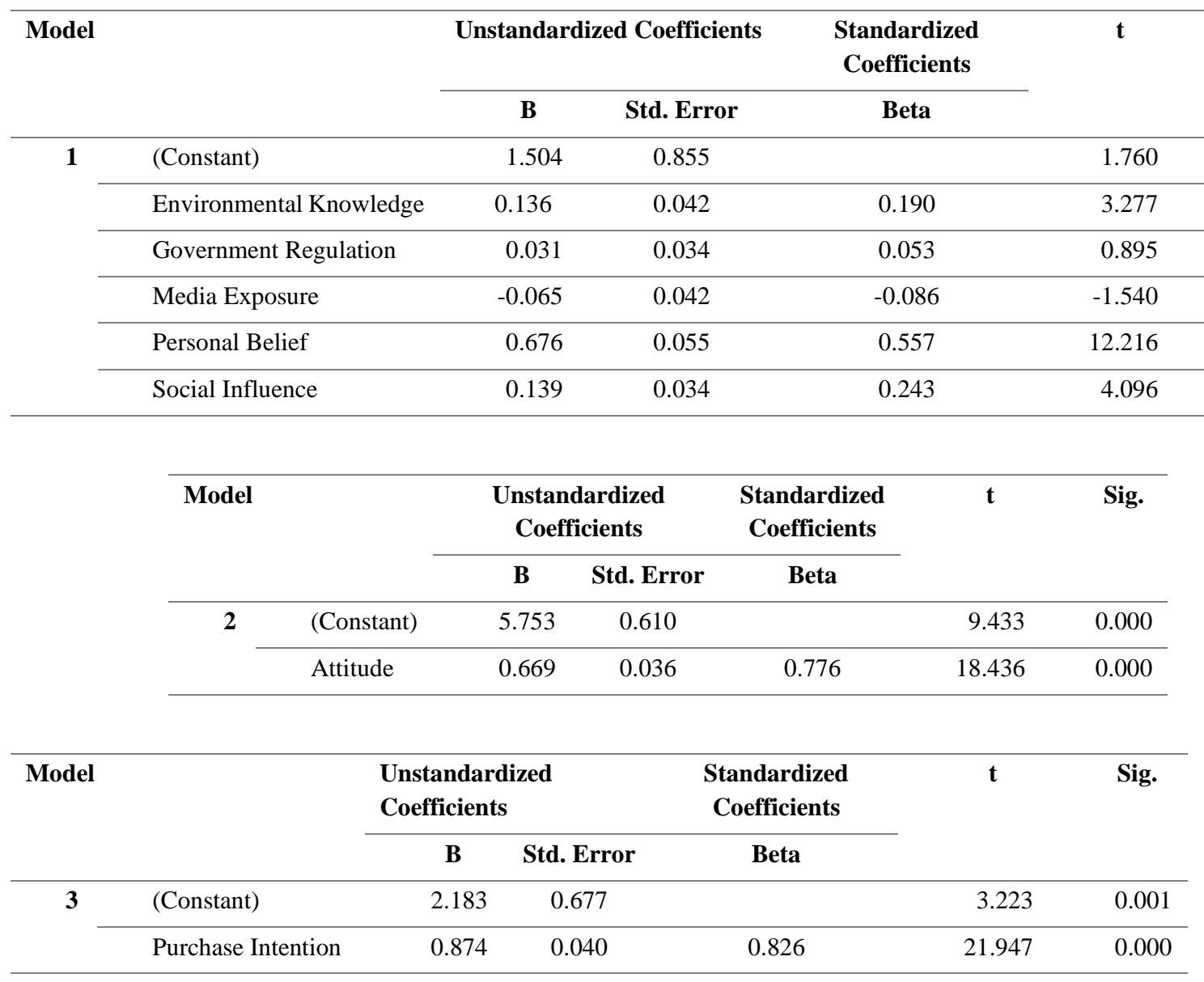

From Table 2, the result of $\mathrm{R}^{2}$ will help to describe how much the influence the independent variables toward the dependent variable in the model. As the result show, the value of $\mathrm{R}^{2}$ is 0.602 which indicate that $60.2 \%$ of purchase intention of reusable shopping bags influenced by attitude. The rest of $39.8 \%$ is influenced by other factors or variables which not included in this model. Furthermore, for model 3, the result of the R-value is 0.826 which means that there is a strong correlation in an overall linear relationship. Based on $\mathrm{R}$ coefficient rules it stated that the value of the coefficient determination is higher than 0.1. Therefore, when the result is greater than 0.1 , meaning that the linear regression is strong. Furthermore, the researchers also analyze the value of the $\mathrm{R}^{2}$. From the table above the result of $\mathrm{R}^{2}$ will help to describe how much the influence the independent variables toward the dependent variable in the model. As the result show, the value of $\mathrm{R}^{2}$ is 0.682 which indicates that $68.2 \%$ of pro-environmental behavior influenced by attitude. The rest of $31.8 \%$ is influenced by other factors or variables which not included in this model.

From the t-test of Environmental Knowledge, it is found that the value is $3.277>\mathrm{t}$-table of 1.651, meaning that the variable is significant and null hypothesis (H0) is rejected while hypothesis 1 is accepted. 
It can be concluded that environmental knowledge has a significant influence on attitude to purchase reusable shopping bags. For Government Regulation, it shows that the value of the t-test is $0.372<\mathrm{t}$-table of 1.651, meaning that the variable is not significant. Therefore, hypothesis 2 is rejected. It can be concluded that the factor government regulation does not have a significant influence on attitude to purchase reusable shopping bags. The Media Exposure variable's (X3) t-test value is $-1.540<\mathrm{t}$-table of 1.651, meaning that the variable is not significant. Thus, hypothesis 3 is rejected. We can conclude that the factor media exposure does not have a significant influence on attitude to purchase reusable shopping bags. The test result of Personal Belief shows that the value of the t-test is $12.216>t$-table of 1.651 , meaning that the variable is significant. Therefore, hypothesis 4 is accepted. It can be concluded that the personal belief has a significant influence on attitude to purchase reusable shopping bags. The Social Influence's t-test value is $4.096>\mathrm{t}$-table of 1.651 , meaning that the variable is significant. Thus, hypothesis 5 is accepted. We can conclude that the factor social influence has a significant influence on attitude to purchase reusable shopping bags. The t-test value of Attitude is $9.433>\mathrm{t}$-table of 1.651, meaning that the variable is significant. Thus, hypothesis 6 is accepted. We can conclude that the attitude factor has a significant influence on attitude to purchase reusable shopping bags. The Purchase Intention's t-test value is 21.947 > $\mathrm{t}$-table of 1.651, meaning that the variable is significant. Thus, hypothesis 7 is accepted. We can conclude that intention to purchase reusable shopping bags has a significant influence on pro-environmental behavior. The research model can be seen in Figure 2.

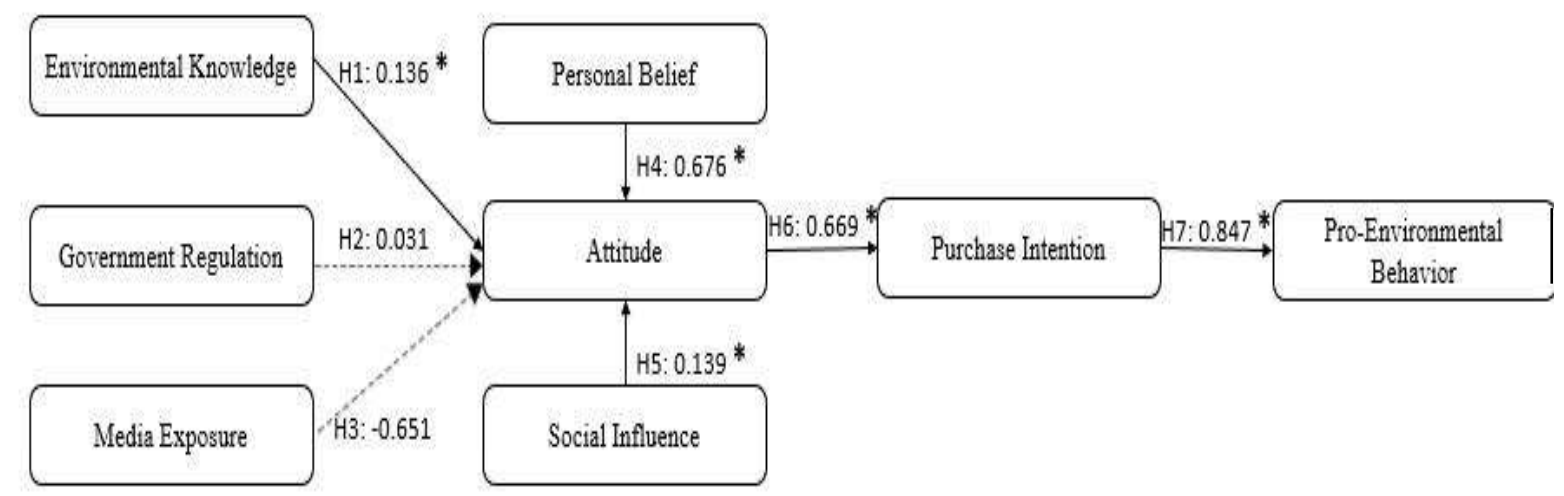

Figure 2. Research Framework

\section{CONCLUSION}

The objective of this study was to analyze the millennials' intention in Bali towards purchasing reusable shopping bags while extending the Theory of Planned Behavior (TPB). Environmental Knowledge, Personal Belief, and Social Influence significantly affect the attitude of customers to purchase reusable shopping bags. Personal Belief becomes the dominant variable affecting the consumer attitude. Meanwhile, Government Regulation and Media Exposure have no significant influence on the consumer attitude to purchase reusable shopping bags. Attitude significantly influences Intention to Purchase reusable shopping bags. Furthermore, Intention to Purchase reusable shopping bags has a significant effect on ProEnvironmental Behavior.

\section{Theoretical Implications}

In model 1, the study discussed the relationship between the attribute of the Theory of Planned Behavior and characteristics of extending variables, e.g., environmental knowledge, government regulation, media exposure, personal belief, and social influence. According to the results, environmental knowledge, personal belief and social influence positively affect attitude to purchasing reusable shopping bags. This 


\section{JOURNAL OF MULTIDISCIPLINARY ISSUES}

Journal Website: www.ojs.ac.id

J. Multidisc. Issues 1(1) xx-Xx (2021)

finding of the study aligns with some previous research. The positive relations between environmental knowledge on attitude to purchasing reusable shopping bags, unlike results from other studies (e.g., Indriani et al., 2019). The finding of this study stated that Environmental Knowledge has no significant direct effect on green purchase intention. Moreover, this study finds out that attitude more important to have a full mediation effect on the relationship of Environmental Knowledge and green purchase intention.

Furthermore, in this 1 model, personal belief and social influence show a positive and significant relation to purchasing reusable shopping bags. This finding of the study was consistent with Indriani et al. (2019), which revealed that personal belief was the most critical contributor to the attitude towards green products. Moreover, Chen et al.'s (2018) study found that social influence positively correlates with attitude to purchase green products. The finding of this study stated that social influence has a significant effect on attitude towards green products.

Model 2 discussed the relationship between attitude and intention to purchase reusable shopping bags. Hence, the regression model shows that attitude positively influences intention to purchase reusable shopping bags. This finding is in line with the study from Chen et al. (2018) that stated that green products' attitude significantly and positively influences purchase intention of green products. Model 3 discussed the relationship between purchase intention with pro-environmental behavior. The regression model shows that purchase intention positively influences pro-environmental behavior. This result also showing consistent results with the Theory of Planned Behavior that explains intention positively influences people's behavior.

\section{Managerial Implications}

Consumers who are knowledgeable about green products and environmentally concerned believe that purchasing green products will benefit the environment's sustainability. Thus, environmental knowledge affecting consumers' evaluations of ecological benefits and their preference for green products will positively affect purchase intention. Therefore, the business should provide environmental information on their mobile software or websites, enhancing a better understanding of green products and preferred evaluations of products that generate environmental benefits and increase intention to purchase the products. In addition, the business can increase intention towards purchasing green products, such as reusable shopping bags, by educating the consumers about environmental protection, which can increase the customer knowledge regarding the environmental concern. Busineses can educate the consumers by conducting activities that are associated with environmental protection and sponsoring environmentalrelated media ads. Hence, this activity would enable consumers to understand the specification of green appliances.

Personal belief also significantly affects consumers attitude to purchasing reusable shopping bags. Thus, this study's result could be considered advice for marketers by enhancing personal belief of the consumers. Therefore, the marketers can create informational campaigns regarding reusable shopping bags or ecofriendly products to protect the environment in social media or advertisements, emphasizing the function of the eco-friendly product to save the environment. Moreover, the information about the products should be widespread in public through various ways of social media to increase the customers' personal belief. Furthermore, the massage must be detail-oriented and clear, for example, how positively it affects the consumer's health and environmental sustainability. Therefore, the company manager also needs to pay more intention to the organic information to attract potential customers which can increase the purchase intention and enhance the loyalty of existing customers. Besides that, the marketer of environmentalfriendly products also suggested enhancing the value of environmental sustainability in every advertisement or packaging of the product. Businesses are suggested to conduct more programs related to environmental protection, such as green campaign competitions. Through this competition, the potential customer will increase their belief that protecting the environment is very important for environmental sustainability.

Social influence also significantly affects consumer attitude to purchase reusable shopping bags as ecofriendly products. Family, friends, and relatives play a key role in affecting the intention to purchase green products. Therefore, the business must emphasize the function and quality of green products. When 
consumers purchase green products, they are aware of the benefit to environment and energy saving, influencing other people to buy the products. Furthermore, the marketing team may want to create a persuasive message to affect social groups or individuals. For instance, the marketing team can point or claim the environmental benefit of eco-friendly products. To increase the intention, persuasive messages can be shared through social media influencers. Hence, the effects of social influence will also provide a business idea to market their products through word-of-mouth communication.

The research only limits the respondents to one area (Bali). The study employs short observation periods and is limited to environmental knowledge, government regulation, media exposure, personal belief, social influence, attitude, and purchase intention. Therefore, the finding of this study only limited to these variables. For future research, comparing other existing green products is advised.

\section{REFERENCES}

Al-shaaban, S. \& Nguyen, T. B. (2014). Consumer Attitude and Purchase Intention towards Organic Food A quantitative study of China Linnæus University. Journal of Consumer Behaviour, 6(2C), 1-67.

Anam, C. (2014). The Impact of Social Influence, Compatibility, and Price on Purchase Intention of Android Smartphone (Unpublished Thesis). Muhammadiyah University, Surakarta, Indonesia.

Arifani, V. M., \& Haryanto, H. (2018). Purchase intention: Implementation theory of planned behavior (Study on reusable shopping bags in Solo City, Indonesia). IOP Conference Series: Earth and Environmental Science, 200(1), 0-6. https://doi.org/10.1088/1755-1315/200/1/012019

Ayodele, A. A., Panama, A. E., \& Akemu, E. (2017). Green Awareness and Consumer Purchase Intention of Environmentally-friendly Electrical Products in Anambra, Nigeria. Journal of Economics and Sustainable Development, 8(22), 98-112.

Bharucha, J. P. (2018). Social media and young consumers behavior. International Journal of Supply Chain Management, 7(6), 72-81.

Chen, C. C., Chen, C. W., \& Tung, Y. C. (2018). Exploring the consumer behavior of intention to purchase green products in Belt and Road countries: An empirical analysis. Sustainability (Switzerland), 10(3). https://doi.org/10.3390/su10030854

Choudhary, M. P., Chauhan G. S., \& Kushwah, Y. K. (2015). Environmental Degradation: Causes, Impacts and Mitigation. Conference Paper National Seminar on Recent Advancements in Protection of Environment and (NSRAPEM) at Maharishi Arvind College Of Engineering and Technology, Kota Rajasthan, India its Management Issues.

Doran, R. \& Larsen, S. (2016). The Relative Importance of Social and Personal Norms in Explaining Intentions to Choose Eco-Friendly Travel Options. International Journal of Tourism Research, 18(2), 159-166.

Fishbein, M. \& Ajzen, I. (1975). Belief, Attitude, Intention, and Behavior: An Introduction to Theory and Research. Addison-Wesley.

Gapura Bali (2019). Bali leads the way and officially bans single-use plastic bags, straws and polystyrene across the island. Retrieved from https://www.gapurabali.com/news/2019/06/25/bali-leads-way-andofficially-bans-single-use-plastic-bags-straws-and-polystyrene

Indriani, D., Rahayu, M., \& Hadiwidjojo, D. (2019). The Influence of Environmental Knowledge on Green Purchase Intention the Role of Attitude as Mediating Variable. International Journal of Multicultural and Multireligious Understanding, 6(2), 627. https://doi.org/10.18415/ijmmu.v6i2.706

Jakarta Post, The (2018). Bali enacts plastics ban, targeting 70 percent reduced use in 2019. Retrieved from https://www.thejakartapost.com/news/2018/12/25/bali-enacts-plastics-ban-targeting-70-percentreduced-use-in-2019.html

Joshi, Y., \& Rahman, Z. (2015). Factors Affecting Green Purchase Behaviour and Future Research Directions. International Strategic Management Review, 3(1-2), 128-143. doi:10.1016/j.ism.2015.04.001 
Kishore, P. K. \& Anand, B. (2013). A Study on Consumer Behavior towards Eco-Friendly Paper. Global Journal of Management and Business Research Administration and Management, 13(11), 8-14.

Lee, Y. K. (2017). A Comparative Study of Green Purchase Intention between Korean and Chinese Consumers: The Moderating Role of Collectivism. Sustainability, 10, 1-17.

Louise (2019). Hot News: Bali has finally instated the ban on single-use plastic! Retrieved from https://thehoneycombers.com/bali/bali-plastic-bag-ban-2019/

Ones, D. S., Wiernik, B. M., Dilchert, S., \& Klein, R. (2015). Pro-Environmental Behavior. In International Encyclopedia of the Social \& Behavioral Sciences: Second Edition (pp. 82-88). Elsevier Inc.. https://doi.org/10.1016/B978-0-08-097086-8.22008-4

Qader, I. K. A. \& Zainuddin, Y. b. (2011). The Impact of Media Exposure on Intention to Purchase Green Electronic Products amongst Lecturers. International Journal of Business and Management, 6(3), 240248.

Pangaribuan, C. H., Dewi, L. Y. I., Ardiansyah, M., Putra, O. P. B., \& Hidayat, D. (2020). Investigation into Millennials' Perceived Environmental Knowledge towards Intention to Use EnvironmentalFriendly Drinking Straws. Proceedings of The $1^{\text {st }}$ International Congress on Regional Development, Information Technology, and Sustainable Business (INCREDIBLE) 2020, 20-33.

Polonsky, M. J., Vocino, A., Grau, S. L., Garma, R., \& Ferdous, A. S. (2012). The impact of general and carbon-related environmental knowledge on attitudes and behaviour of US consumers. Journal of Marketing Management, 28(3-4), 238-263. doi:10.1080/0267257x.2012.659279

Schultz, P. W. \& Lauterborul, Z. C. (1993). Values and pro environmental behavior: A five -country survey. Journal of Cross-Cultural Psychology, 29(4), 540-558.

Whaley, J. E. \& Costen, W. M. (2019). Personal and Social Tipping Norms: Race and Sex Differences. International Journal of Marketing Studies, 11(3), 1.

Zhang, L., Fan, Y., Zhang, W., \& Zhang, S. (2019). Extending the theory of planned behavior to explain the effects of cognitive factors across different kinds of green products. Sustainability, 11(15), 1-17. https://doi.org/10.3390/su11154222 